\title{
REFLECTIONS
}

\section{Promoting Participatory Research by Family Physicians}

Ann C. Macaulay, CM, MD, FCFP

McGill University, Montreal, Quebec, Canada
Conflicts of interest: none reported

\section{CORRESPONDING AUTHOR}

Ann C. Macaulay, CM, MD, FCFP

Participatory Research at McGill (PRAM)

Department of Family Medicine

McGill University

515 Pine Ave West

Montreal, Quebec H2W 1S4

ann.macaulay@mcgill.ca

\begin{abstract}
In the past, researchers have inadvertently caused stigmatization of various populations, first by not involving community members and then through publishing negative findings. In contrast, participatory research, which is based on a partnership between researchers and those affected by the issue being studied, promotes the voice of those being researched. This essay highlights key principles, processes, complexities, and challenges of participatory research and outlines when participatory research is not appropriate. It also reflects on the training and skills of family physicians that make them especially suited to participatory research. Family physicians have established clinical partnerships with their patients and sometimes entire communities, are trained in patient-centered care-a good basis for community centered research-and are accustomed to working with uncertainty. In addition, they are frequently pragmatic, interested in questions arising from their patients and communities, and likely to respond well to community requests. The main challenges to participatory research are lack of funding, expertise, and time, which may improve as more funding agencies and universities support this approach to research.
\end{abstract}

Ann Fam Med 2007;5:557-560. DOI: 10.1370/afm.755.

\section{INTRODUCTION}

$\mathrm{F}$ amily physicians work in a wide variety of settings, including com-

$\checkmark$ munities identifiable by geography or ethnicity, private offices, managed care practices, and academic teaching centers. They take care of patients from all walks of life, including those from poor, vulnerable, and minority populations. Some family physicians-both practice- and university-based-are also engaged in primary care research. If they are already engaged in research or thinking of becoming so engaged, I would like to advocate that they consider using participatory research. Participatory research is defined as researchers working in partnership with "those affected by the issue under study"1 and is increasingly recognized as a highly effective method of adding relevance and value to primary health care research. ${ }^{2}$ The equally important goals of participatory research are to undertake high-quality research, benefit the community or group where the research is occurring, and develop knowledge applicable to other settings. This essay highlights the key points and challenges of participatory research, shows how this approach to research can be applied in different settings and with different populations, and describes why I believe family physicians are ideally suited to succeed in this type of research.

\section{Need for Participatory Research}

Communities, especially of poor, vulnerable, and minority populations, are often stigmatized by those who conduct research on or in or about communities. Community has been defined as "a group of people sharing 
a common interest. Cultural, social, political, health, and/or economic interests link the individuals, who may or may not share a particular geographic association."1 Communities can be geographic entities, organizations (eg, health care organizations), or groups of individuals. Individuals may not necessarily belong to a community with social interactions, but they can become a community of convenience for a research project, such as patients attending an academic teaching center. Conventional research, in which researchers make all the decisions, can be detrimental to communities that have no input and are objectified during the process, do not receive the findings, and are stigmatized by dissemination of negative results. Furthermore, researchers often fail to put their findings into context or recommend how results can promote programs to improve health.

In contrast, participatory research engages researchers and community members in an active research partnership. In its fullest expression the researchercommunity partnership creates a team for decision making throughout the research process, from developing the question; collecting, analyzing, and interpreting the data; and developing conclusions to disseminating results. Researchers and community members each bring their own expertise, backgrounds, and different knowledge base to the team. It is this combination of strengths that is so enriching to the process, both benefiting the community and increasing the scientific validity of the findings. ${ }^{3,4}$ Participatory research promotes research relevant to local concerns, action and social change, increased community skills, capacity building, sustainability, and knowledge translation. ${ }^{5}$

\section{Participatory Research Process}

There are many aspects to the process of conducting participatory research: community definition and representation; forming a community advisory group that reflects community diversity; defining, prioritizing, and negotiating community concerns and research tasks; managing and disseminating controversial or even stigmatizing results; and issues of control and power. These concerns are key in any community-researcher relationship and have been explored in some detail elsewhere. ${ }^{6-10}$ Ideally the process uses a written agreement, ${ }^{4,11}$ builds on preexisting strengths, facilitates collaborative partnerships, promotes a cyclical and iterative process with conjoint learning, addresses health from a positive perspective, and disseminates findings and knowledge gained to all partners. ${ }^{12}$ The fundamental shift required by researchers is to move from thinking that they are the experts to an understanding that they have expertise which complements the expertise of other team members. ${ }^{13,14}$

\section{Participatory Research in Different Settings and With Varying Topics}

It is easier to initiate participatory research when there is a natural community with which to partner. ${ }^{15,16}$ Even so, participatory research has also been undertaken with highly diverse groups, including the homeless, ${ }_{1}^{17}$ women prisoners, ${ }^{18}$ health care workers working with children receiving palliative care at home, ${ }_{1}^{19}$ and minority groups, ${ }^{20}$ as well as across large geographic areas of practice-based research networks. ${ }^{21}$ It has also been used with potentially stigmatizing research topics, including pregnant women abusing drugs, ${ }^{22}$ alcohol use, ${ }^{23}$ immigrants, and indigenous peoples with tuberculosis. ${ }^{24}$ Using participatory research with marginalized communities and stigmatizing topics promotes findings more relevant to those who are the subjects of the research and, with all team members contributing to and/or reviewing material before external dissemination, ensures that information is released with community agreement.

\section{When Participatory Research Is Not Appropriate} There are also situations in which a participatory approach may not be necessary or appropriate, such as analyses of national data sets or when representation is particularly hard to achieve. A balance should be maintained between the need for representation and the practicality of time and funding. Assuring representation from widely disparate groups could overburden resources and bring research to a halt.

\section{Family Physicians and Participatory Research}

For the following reasons, I believe that family physicians have unique background skills and are well positioned to undertake participatory research:

- Established relationships. Researchers first need to develop a partnership with those affected by the issue under investigation. Through providing health care, family physicians have already established trusting relationships with individuals, organizations, and, indeed, entire communities. Also, a community has had time to size up their family physicians and assess the advantages or disadvantages of extending this relationship to include research.

- Skills. Some family physician skills are relevant to participatory research. For example, family physicians are taught to use a patient-centered approach. Such an approach includes developing a shared agenda for patient care, including an understanding of the wider context of each patient-everything from the genetic heritage to family and workplace stressors. I suggest that patient-centered care is a good basis for participatory research, which is patient- or community-centered research. Participatory research requires discussions 
among team members to develop a shared research agenda and a deeper understanding of community or group complexities.

- Experience with uncertainty. Family physicians are also accustomed to dealing with uncertainty, as their patients have a wide variety of undifferentiated symptoms: Is this headache due to socioeconomic issues or underlying disease? Should I treat them myself or should I refer? In participatory research projects there is plenty of uncertainty as team members come together with different backgrounds and world views. Will all partners continue to agree on the direction of the research? Will key stakeholders remain in the partnership until the end? Will all partners interpret or value the results the same way? I remember an excellent family physician researcher moving from conventional research to $\mathrm{PR}$. When he said he felt he was holding a "ball of unset Jell-O," I absolutely agreed. I suggest this sensation is parallel to the uncertainties of patient care.

- Pragmatism. Family physicians frequently seem to be pragmatic - another trait that aids participatory research, in which decisions and power are shared. When a family physician develops a research idea, he or she is likely to want to research something that has come out of patient care or is common in the practice. Such a research idea is also likely to be of interest to community members. Alternatively, if the question comes from the community, it is likely to resonate with the family physician. In contrast, academic researchers often have questions that would be interesting to investigate but are not perceived to be of value to community members.

- Resource for research. Communities see family physicians as a resource of knowledge, skills, and contacts and may approach them for help in evaluating or ameliorating a health problem. ${ }^{25}$ Family physicians with research skills and time can themselves suggest using participatory research to address a community issue. Other family physicians may bridge the divide between the community and academic institutions by linking community members to available participatory researchers.

- Combining patient care and research. Wearing 2 hats by seeing patients and undertaking research grounds the family physician researcher in a greater reality. It is much easier to suggest blood tests for children from an ivory tower than when working in the community where patients, who are also parents and grandparents, are questioning invasive investigations. Physicians should always reflect on whether there are conflicts between patient care and research, and ensure that patients and their families do not feel pressured to take part in research. The participatory research process may help when patients can discuss any concerns with their representatives on the research team.

- Expertise in knowledge translation. Research includes translating scientific results to community and policy makers, and family physicians have expertise in explaining complex scientific concepts in communityfriendly language.

\section{Challenges of Participatory Research}

There are many challenges in participatory research, including those of time and funding. Finding time to undertake research is difficult. Even more difficult is finding paid and protected time, especially for participatory research, which requires additional time first to build and then to maintain the partnerships. For practicing physicians the current climate of primary care is leaving less time for activities not directly focused on patient care. Academic researchers struggle with the unfunded costs, time commitment, and lack of recognition of participatory research for promotion and tenure. ${ }^{26}$ Undertaking participatory research is often internally motivated, and the greatest reward comes from the work itself, as only occasionally are there academic, practice, or real-world rewards.

Practicing family physicians who believe they lack research training might be able to find a sympathetic university partner who is knowledgeable or at least open to participatory research, but doing so may not be possible, because not all universities support this approach to research. Other resources to consider include organizations committed to promoting participatory research. ${ }^{27}$ Funding remains a challenge, as to date no research funding agencies recognize and support the up-front costs of developing the partnerships. Funding for participatory research continues to improve, however, and other new developments, including clinical and translational science awards in the United States, might also support this approach to research.

The knowledge being exchanged among all team members makes participatory research highly rewarding. A need for capable participatory research practitioners will continue to grow as more communities, groups, and marginalized populations take control of addressing their own pressing health and social issues. At the same time, an increasing number of funding agencies are calling for a participatory research approach to be integrated into research methods, which will lead academic researchers to seek out professional partners who are more comfortable working with participatory research. All these developments are encouraging interested family physicians to take up the mantle of participatory research for the benefit of primary care research and society at large. 


\section{To read or post commentaries in response to this article, see it} online at http://www.annfammed.org/cgi/current/full/5/6/557.

Key words: Participatory research; community-based research; action research; family physicians; community-based participatory research

Submitted February 1, 2007; submitted, revised, July 24, 2007; accepted August 2, 2007

\section{References}

1. Green LW, George A, Daniel M, et al. Study of Participatory Research in Health Promotion: Review and Recommendations for the Development of Participatory Research in Health Promotion in Canada. Ottawa: Royal Society of Canada; 1995:4

2. Committee on Educating Public Health Professionals for the 21st Century. Gebbie K, Rosenstock L, Hernandez LM. Who Will Keep the Public Healthy? Educating Public Health Professionals for the 21st Century. Brief Reports. Washington, DC: Institute of Medicine; 2002 http://www.iom.edu/CMS/3793/4723/4307.aspx.

3. Wallerstein NB, Duran B. Using community-based participatory research to address health disparities. Health Promot Pract. 2006;7(3):312-323

4. Macaulay AC, Commanda LE, Freeman WL, et al. Participatory research maximises community and lay involvement. BMJ. 1999;319(7212):774-778.

5. Glasgow RE, Emmons KM. How can we increase translation of research into practice? Types of evidence needed. Annu Rev Public Health. 2007;28:413-433.

6. Minkler M, Wallerstein N, eds. Community Based Participatory Research for Health. San Francisco, Calif: Jossey-Bass; 2002.

7. Minkler M. Ethical challenges for the "outside" researcher in community-based participatory research. Health Educ Behav. 2004;31(6):684-697.

8. Stevenson J, Cifuentes M. Recent Publications Regarding Community-based Participatory Research (CBPR). http://www.fmdrl.org/879. Family Medicine Digital Resource Library; 2007.

9. Israel BA. Methods in Community-Based Participatory Research for Health. San Francisco, Calif: Jossey-Bass; 2005.

10. Jones $L$, Wells $K$. Strategies for academic and clinician engagement in community-participatory partnered research. JAMA. 2007;297(4):407-410

11. Herbert CP. Community-based research as a tool for empowerment: The Haida Gwaii Diabetes Project example. Can J Public Health. 1996;87(2):109-112.

12. Israel BA, Schulz AJ, Parker EA, Becker AB. Review of communitybased research: assessing partnership approaches to improve public health. Annu Rev Public Health. 1998;19:173-202.
13. Chene R, Garcia L, Goldstrom M, et al. Mental health research in primary care: Mandates from a community advisory board. Ann Fam Med. 2005;3(1):70-72.

14. Westfall JM, VanVorst RF, Main DS, Herbert C. Community-based participatory research in practice-based research networks (Supplemental case report). Ann Fam Med. 2006;4(1):8-14. http://www. annfammed.org/cgi/content/full/4/1/8/DC1.

15. Macaulay AC, Paradis G, Potvin L, et al. The Kahnawake Schools Diabetes Prevention Project: intervention, evaluation, and baseline results of a diabetes primary prevention program with a native community in Canada. Prev Med. 1997;26(6):779-790.

16. Corbie-Smith G, Ammerman AS, Katz ML, et al. Trust, benefit, satisfaction, and burden: a randomized controlled trial to reduce cancer risk through African-American churches. J Gen Intern Med. 2003;18(7):531-541.

17. Buck DS, Rochon D, Davidson H, McCurdy S. Involving homeless persons in the leadership of a health care organization. Qual Health Res. 2004;14(4):513-525.

18. Martin R, Hislop G, Ogilvie G, et al. Participatory Research with Women in Prison to Improve Health. 19th IUHPE World Conference on Health Promotion and Health Education. Vancouver, BC, 2007

19. Mongeau S, Champagne M, Liben S. Participatory research in pediatric palliative care: benefits and challenges. J Palliat Care. 2007;23(1):5-13.

20. Lam TK, McPhee SJ, Mock J, et al. Encouraging Vietnamese-American women to obtain Pap tests through lay health worker outreach and media education. J Gen Intern Med. 2003;18(7):516-524.

21. Westfall JM, VanVorst RF, Main DS, Herbert C. Community-based participatory research in practice-based research networks. Ann Fam Med. 2006;4(1):8-14

22. Baldwin JH, Rawlings A, Marshall ES, Conger CO, Abbott KA. Mom empowerment, too! (ME2): a program for young mothers involved in substance abuse. Public Health Nurs. 1999;16(6):376-383.

23. Mohatt GV, Hazel KL, Allen J, Stachelrodt M, Hensel C, Fath R. Unheard Alaska: culturally anchored participatory action research on sobriety with Alaska Natives. Am J Community Psychol. 2004;33(3-4):263-273.

24. Gibson N, Cave A, Doering D, Ortiz L, Harms P. Socio-cultural factors influencing prevention and treatment of tuberculosis in immigrant and Aboriginal communities in Canada. Soc Sci Med. 2005;61(5):931-942.

25. Bissett S, Cargo M, Delormier T, Macaulay AC, Potvin L. Legitimizing diabetes as a community health issue: a case of an Aboriginal community in Canada. Health Promot Int. 2004;19(3):317-326.

26. Nyden P. Academic Incentives for Faculty Participation in Community-based Participatory Research. J Gen Intern Med. 2003;18(7):576585.

27. Community Campus Partnerships for Health. http://www.ccph.info. 